\title{
Growth in the Chick Embryo of Strains of Trachoma and Inclusion Blennorrhoea Virus of Differing Virulence
}

\author{
By JANICE TAVERNE, W. A. BLY'TH AND P. REEVE \\ M.R.C. Trachoma Research Unit, Lister Institute of Preventive \\ Medicine, Chelsea Bridge Road, London, S.W.1
}

\begin{abstract}
SUMMARY
The growth in the chick embryo yolk sac of trachoma and inclusion conjunctivitis (TRIC) strains which differ in virulence for the chick embryo was measured in terms of ELD 50 inclusion forming units in HeLa cells and total particles. Observed differences in rates of growth are consistent with the assumption that greater virulence depends on a higher rate of multiplication in the chick embryo. All strains were equally labile when heated at $37^{\circ}$ in vitro but only the more virulent kill chick embryos at $37^{\circ}$.
\end{abstract}

\section{INTRODUCTION}

The capacity of a micro-organism to kill is covered by the term virulence, and virulence may be determined by toxigenicity, invasiveness, or many other factors and is qualified by the host in which it is measured (Topley \& Wilson's Principles, 1964). Strains of trachoma and inclusion conjunctivitis (TRIC) agents differ in ability to kill chick embryos when inoculated into the yolk sac, some strains killing more quickly than others when the same number of infectious units are injected (Reeve \& Taverne, 1963). These faster killing strains may be regarded as more virulent for the chick embryo. We are interested in the factors determining the virulence of TRIC agents for the chick embryo. Previously, we suggested that differences in virulence might depend on differences in toxicity (Reeve \& Taverne, 1963), but subsequently found that elementary bodies of strains of differing virulence contained the same amount of toxin (Taverne, Blyth \& Reeve, 1964). Like Jawetz \& Hanna (1960) we concluded from the analysis of dose-response curves that all strains tested multiplied at the same rate. However, eggs infected with a small dose of more virulent strains die 2-3 days earlier than those infected with a similar dose of less virulent strains, yet in each instance the yolk sacs at death contain $10^{9}-10^{10}$ elementary bodies (Reeve\& Taverne, 1963; Taverne, Blyth\& Reeve, 1964). This implies that the growth pattern of the more virulent strains must differ in some way. For instance, the lag before exponential growth or the interval between the end of exponential growth and the death of the embryo might be shorter, or the growth rate might be faster. Jawetz, Hanna, Chino \& Zichosch (1962) measured growth rates directly in eggs and concluded that they did not vary significantly with the strains tested. Since minor variations in the mode of growth might account for the differences observed, we investigated the growth in the chick embryo yolk sac of strains of differing virulence by titrating virus in eggs and in HeLa cells, and estimating the total number of elementary bodies. 


\section{METHODS}

TRIC agents are named according to the system proposed by Gear, Gordon, Jones \& Bell (1963). Their original names used in this paper are given in brackets. Fast-killing variants are suffixed $f$.

TRIC/China/Peking-2/OT (T'ang, Chang, Huang \& Wang 1957).

TRIC/2/SAU/HAR-2/OT (SA2) (Murray et al. 1960) received from Miss L. Hanna, University of California Medical Center, San Francisco. The variant, SA $2 f$, derives from material received from Dr S. Bell, School of Public Health, Harvard University. TRIC/ /WAG/MRC-1/OT (G1) (Collier \& Sowa, 1958).

TRIC/ /WAG/MRC-187/OT (G 187) isolated in the Gambia, British West Africa, from a patient with trachoma.

TRIC/ /WAG/MRC-062/OT (G 062) isolated in the Gambia, British West Africa, from a patient with trachoma.

TRIC/ /GB/MRC-4/ON (LB4) (Jones, 1961) and the variant LB $4 f$.

TRIC/ /USA-Cal/Cal-1/OT (BOUR) (Hanna, Jawetz, Thygeson \& Dawson, 1960).

TRIC/ /GB/MRC/1/G (LB1) (Jones, Collier \& Smith, 1959).

Diluent: phosphate buffered saline (Dulbecco \& Vogt, 1954) containing streptomycin sulphate $1000 \mu \mathrm{g} . / \mathrm{ml}$.

Virus suspensions: $10 \%$ or $20 \%(\mathrm{w} / \mathrm{v})$ suspensions were made by shaking infected yolk sacs in diluent and then discarding the membranes.

Virus titrations were done in 7-day chick embryos kept at $35^{\circ}$ and candled daily. The tests were terminated on the twelfth day after inoculation. Titres are expressed in terms of $\mathbf{5 0} \%$ lethal dose for eggs (ELD 50; Reed \& Muench, 1938). Specificity of death, when doubtful, was determined by examining yolk sac smears for elementary bodies. Virus was titrated in HeLa cells (Furness, Graham \& Reeve, 1960) and titres are expressed in terms of inclusion-forming units (IFU).

Particle counts were made by the dark-field method of Reeve \& Taverne (1962) except that treatment with trypsin was omitted and suspensions were purified by centrifugation at $8000 \mathrm{~g}$ for $20 \mathrm{~min}$. in $\mathrm{M}-\mathrm{KCl}$.

\section{RESULTS}

Growth curves. The growth of 6 strains in the chick embryo yolk sac at $35^{\circ}$ was investigated. For each strain, fifty 7 -day eggs were injected with a dose of virus chosen to kill the embryos as late as possible. Daily, yolk sacs were taken from 3 live embryos, pooled and shaken with a measured volume of diluent; the suspension was titrated in eggs and HeLa cells, and the total number of particles estimated. Growth curves plotted to show the increase in infectious virus during the course of infection are given for 4 strains in Fig. 1. The total particle counts for all 6 strains and the elementary body:infectious virus ratios are presented in Table 1 . With no strain was virus detected before the second day of infection. From the second daythe number of ELD 50 doses increased exponentially to reach a maximum at the mean death time of each group of eggs. During the last 4 days of growth elementary bodies were sufficiently numerous to be counted by the dark ground technique, and, with the more virulent strains, enough virus was present by the fourth day to be 


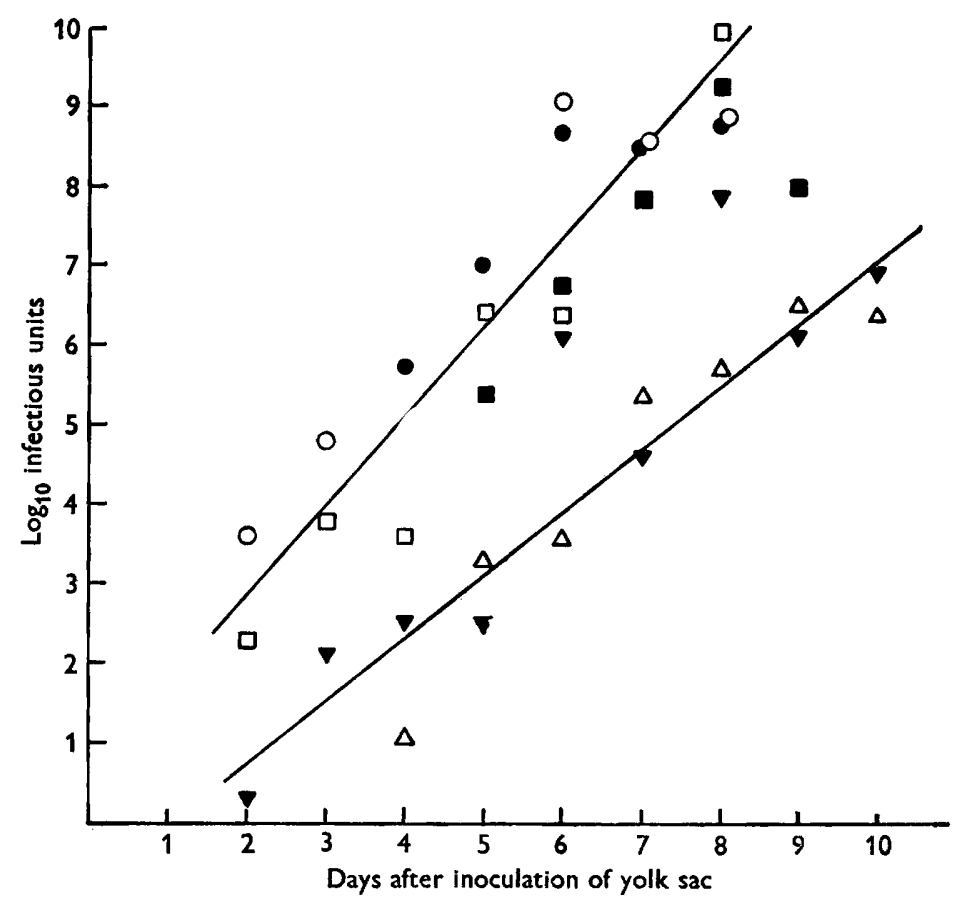

Fig. 1. Growth in yolk sac of two virulent TRIC agents and two less virulent strains. Infecting doses: T'ang $10^{1.3}$ ELD 50, LB4 $10^{1.6}$ ELD 50, SA2f $10^{1.7}$ ELD 50, SA2 10 ${ }^{1.4}$ ELD 50. $\square$, T'ang ELD 50; $\square$, T'ang IFU; O, SA2fELD 50; O, SA $2 f$ IFU; $\triangle$ LB4. ELD 50; $\nabla$, LB4 ELD 50. The lines drawn are best fits derived by a method of least recorded squares.

Table 1. The growth of six TRIC agents in the chick embryo yolk sac Doses inoculated and mean death time are shown in Table 2.

Particle numbers for egg LD 50 (ELD 50) or inclusion-forming units (IFU) per yolk sac (YS) are recorded as $\log _{10}$.

Fast-killing strains

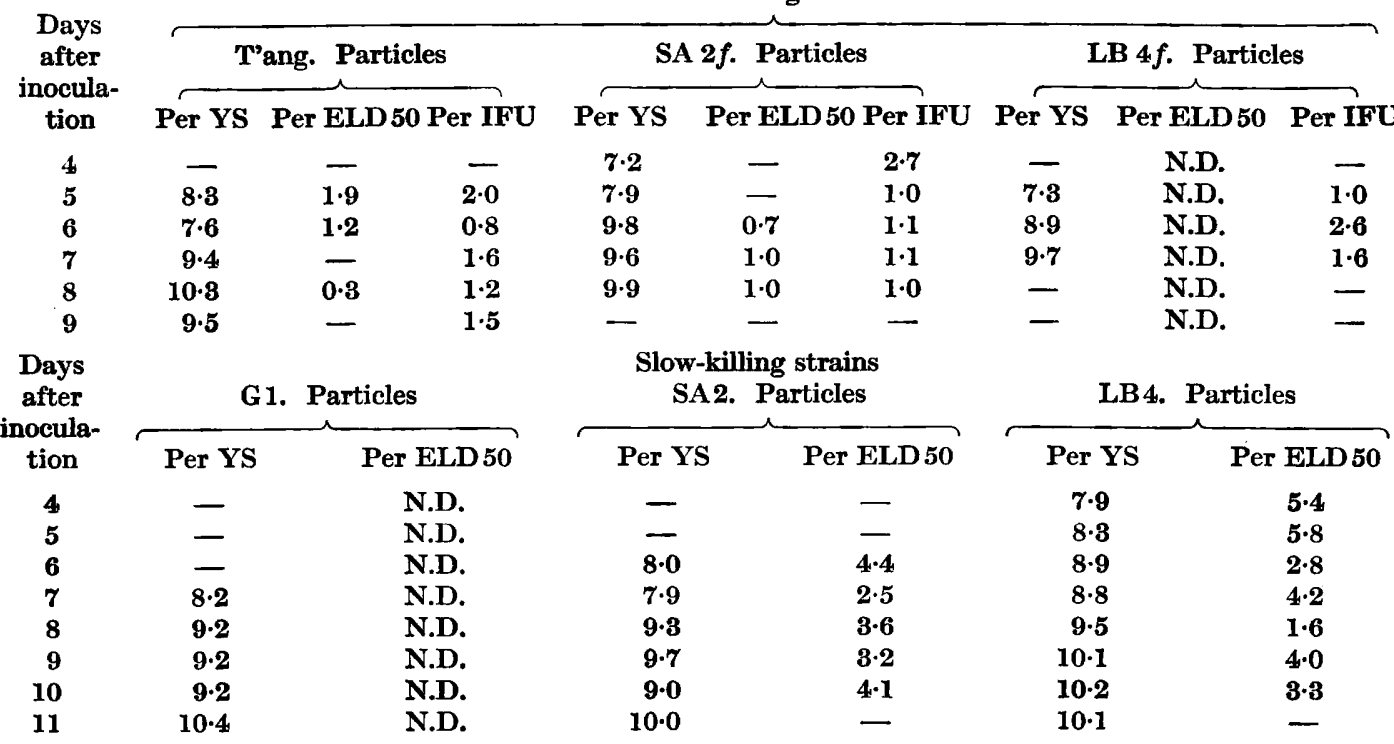


detected as inclusion-forming units in HeLa cells. From then on the infectivity of suspensions was the same in HeLa cells as in eggs, and growth curves measured in IFU were similar to those measured in ELD 50. The less virulent strains did not form enough inclusions to be counted except at the end of the growth when some suspensions with very large amounts of virus infective for eggs $\left(10^{7}\right.$ ELD 50 per yolk sac) contained a small proportion of inclusion-forming units (about $10^{5}$ IFU per yolk sac). The slopes of the growth curves differed, virulent strains apparently increasing at a faster rate than the less virulent (Table 2).

Table 2. Rates of increase of six TRIC strains growing in the chick embryo yolk sac

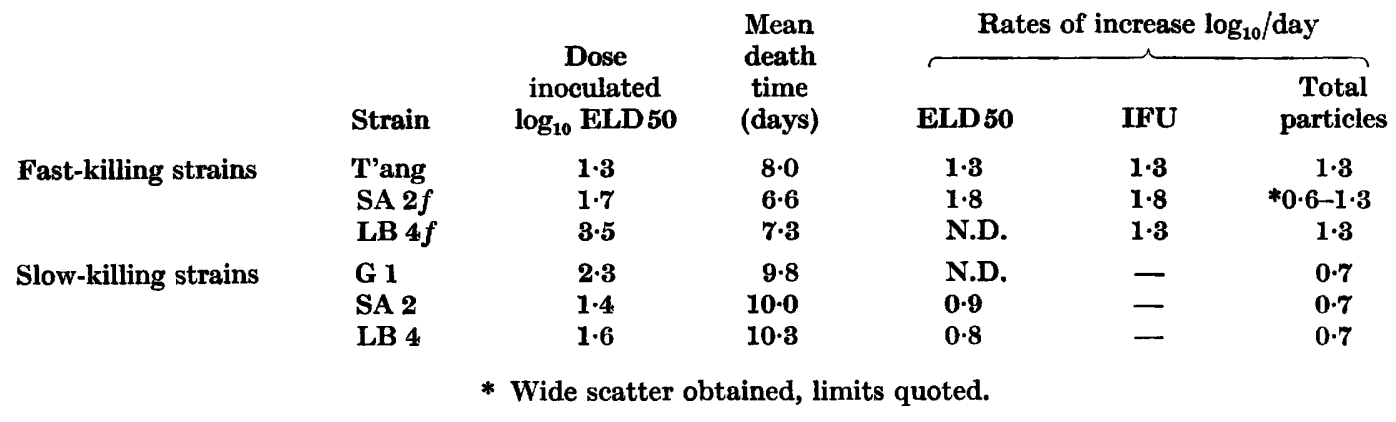

Table 3. Titration of yolk sac suspensions in chick embryos at $35^{\circ}$ and $37^{\circ}$

\begin{tabular}{|c|c|c|c|}
\hline & Strain & $\begin{array}{c}\text { ELD 50 per ml. } \\
\text { at } \mathbf{3 5}^{\circ}\end{array}$ & $\begin{array}{c}\text { ELD } 50 \text { per ml. } \\
\text { at } \mathbf{3 7 ^ { \circ }}\end{array}$ \\
\hline $\begin{array}{l}\text { Fast-killing } \\
\text { strains }\end{array}$ & $\begin{array}{l}\text { T'ang } \\
\text { SA2f } \\
\text { LB4f } f \\
\text { LB } 1\end{array}$ & $\begin{array}{l}4 \cdot 8 \\
7 \cdot 0 \\
6 \cdot 9 \\
5 \cdot 6\end{array}$ & $\begin{array}{l}4 \cdot 8 \\
6 \cdot 6 \\
6 \cdot 6 \\
5 \cdot 6\end{array}$ \\
\hline $\begin{array}{l}\text { Slow-killing } \\
\text { strains }\end{array}$ & $\begin{array}{l}\text { G1 } \\
\text { SA2 } \\
\text { SA2* } \\
\text { LB4 } \\
\text { G 062 } \\
\text { G187 } \\
\text { BOUR }\end{array}$ & $\begin{array}{l}3 \cdot 0 \\
5 \cdot 8 \\
5 \cdot 6 \\
2 \cdot 7 \\
5 \cdot 2 \\
4 \cdot 5 \\
4 \cdot 6\end{array}$ & $\begin{array}{l}\text { Nil } \\
4 \cdot 7 \\
3 \cdot 9 \\
\text { Nil } \\
\text { Nil } \\
0 \cdot 5 \\
\text { Nil }\end{array}$ \\
\hline
\end{tabular}

* Calculated from data of Bell et al. (1963).

Although similarnumbers of ELD 50 doses were inoculated, the more virulent strains always yielded more infective virus. However, at the mean death time of each group of embryos, yolk sacs infected with any strain contained about the same number of elementary bodies. During the latter part of growth, when elementary bodies could be counted, the ratio of total particles:ELD50 was on average 10 for more virulent strains and 5000 for less virulent strains (Table 1). One explanation for this finding is that the less virulent strains are more susceptible to heat. Accordingly, tests were made of the behaviour of the strains at different temperatures.

Titrations at different temperatures. For each strain one set of dilutions was used to inoculate two sets of eggs, which were then incubated at $35^{\circ}$ and $37^{\circ}$ respectively. 


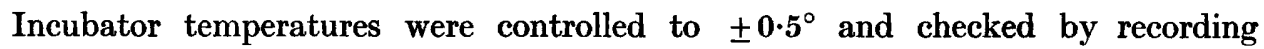
thermometers. A high ambient humidity was maintained. The infectivity of the more virulent strains was measurable at $37^{\circ}$ and titres, although lower, were within threefold of those at $35^{\circ}$ (Table 3 ). By contrast, the less virulent strains, except $\mathrm{SA} 2$, failed to kill chick embryos at $37^{\circ}$; since their titres at $35^{\circ}$ ranged from $10^{2 \cdot 7}$ to $10^{5.2}$ ELD 50 per ml. there was at least 1000 -fold difference in titre. The titre of strain SA 2 at $37^{\circ}$ was ten-fold lower than at $35^{\circ}$. Differences in virulence were thus reflected by differences in killing power at $37^{\circ}$; only the more virulent strains--and SA 2-killed embryos at $37^{\circ}$.

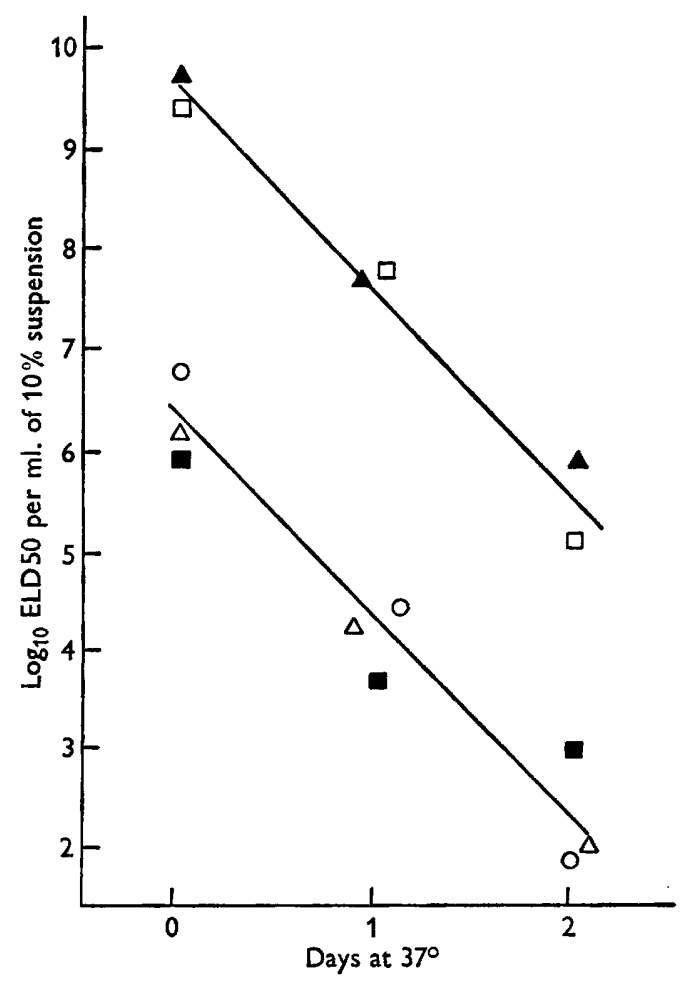

Fig. 2. Inactivation in vitro of six TRIC agents at $37^{\circ} . \triangle$, SA2 $f$ pool 1; $\triangle$, SA2 $f$ pool 2; $\square, \mathrm{LB} 4 f ; 0, \mathrm{Gl} ; \mathbf{m}, \mathrm{LB} 4$.

Heat inactivation. Ten per cent $(w / v)$ suspensions of infected yolk sacs in diluent were kept in a water bath at $37^{\circ}$ and titrated at intervals for infectivity. The strains tested did not vary significantly in rate of inactivation (Fig. 2), all decreasing in infectivity by 100-300 ELD50 per day.

\section{DISCUSSION}

We investigated several TRIC agents to determine whether differences in growth rates in the chick embryo were related to virulence. Variations in the initial lag, before exponential growth began, were insufficient to explain the difference of 2-3 days observed in the time to death of embryos infected with fast- and slow- 
killing strains. Furthermore, there was no interval between the attainment of maximum virus titres and embryo death. When yolk sacs contained most virus, measured in terms of ELD 50, IFU or total particles, the infected embryos began to die. Toxin, titrated in mice or in guinea-pig skin, also reached its maximum at this time (Taverne et al. 1964).

We considered the significance of the small differences in growth rate observed during the exponential phase of multiplication. Theoretically, with a small infecting dose, a strain that shows a daily twentyfold increase in the number of particles would produce $10^{9}-10^{10}$ particles $7-8$ days after inoculation, if there were no lag before exponential increase. With a daily tenfold increase, this number of particles would be produced in $\mathbf{1 0}$ days. Thus a difference of only twofold in the rate of multiplication would account for a difference of 2-3 days in the time at which the strains attained maximum titres of $10^{9}-10^{10}$. The formal demonstration of a statistically significant difference in the slopes shown in Fig. 1 would require a prohibitive number of replicate experiments. However, the observed difference, if real, is sufficient to account for the difference in killing time. It is understandable that small differences in growth rate have not been considered significant (Jawetz \& Hanna, 1960; Jawetz et al. 1962; Reeve \& Taverne, 1963) because titration techniques used are insufficiently precise. Micro-organisms of the psittacosis-lymphogranuloma group are known to have a complicated life cycle, initial forms dividing to produce elementary bodies. The differences in growth rate observed need not only imply differences in the rate of fission; they could result from variations in the mode of division-for instance in the number of elementary bodies derived from each initial form. Again, the growth curves are the results of many cycles of infection, and if strains differed in the efficiency with which they entered cells, a more invasive strain would appear more virulent without necessarily having a different intracellular growth cycle.

Throughout growth the virulence, in terms of organisms per ELD50, was unchanged, in both the less virulent strains with an ELD50 of 5000 and the more virulent strains with an ELD50 of 10 organisms. In addition, the ratio of elementary bodies to infective virus was constant for all strains, suggesting that there was no progressive inactivation in vivo.

With some microbes, the more virulent strains are characterized by capacity to grow over a wider temperature range than the less virulent. Thus Dubes \& Wenner (1957) found that virulent strains of poliovirus grew more efficiently at $39^{\circ}$ than attenuated strains. Nizamuddin \& Dumbell (1961) showed that variola major virus produces pocks on the chick chorioallantois at $39^{\circ}$, whereas the less virulent variola minor virus does not. Bedson \& Dumbell (1961) discovered that the virulence of pox virus strains in terms of ability to kill chick embryos is related to the highest temperature ('ceiling temperature') at which they will grow. We did not determine the ceiling temperatures of our strains, but found that only the more virulent strains-and SA2-killed chick embryos at $37^{\circ}$. Our results with strain SA 2 are similar to those of Bell, Murray, Carroll \& Snyder (1963). This strain killed chick embryos at $37^{\circ}$ but there were fewer ELD 50 doses than at $35^{\circ}$. The figures given by Bell and co-workers show that embryos inoculated with a given dose of SA2 and incubated at $37^{\circ}$ regularly died $2-3$ days earlier than those incubated at $35^{\circ}$, as we also observed. The effects of a higher temperature of incubation on SA2 were thus 
twofold: titres were lower and chick embryos died more quickly. Only with strain SA2 was this shortening in time of response observed. With more virulent strains dose-response curves plotted from titrations at $35^{\circ}$ were similar to those obtained from titrating at $37^{\circ}$. It seems likely that strain SA2 is heterogeneous, containing particles that differ in ability to kill chick embryos at different temperatures. Our results emphasize the importance of controlling incubator temperatures within narrow limits, as already stressed by Bell et al. (1963), since suspensions usually contained fewer ELD 50's at $37^{\circ}$ and in many cases failed to kill embryos.

As with the pox strains tested by Bedson \& Dumbell (1961), differences in the ability to grow at higher temperatures do not appear to depend on differences in the rate of inactivation by heat, all strains being equally labile when heated at $37^{\circ}$ in vitro. Reeve \& Taverne (1963) established that strains of relatively greater virulence for the chick embryo can also form inclusions in HeLa cells and that some of them can multiply in the mouse brain. We have now added another character associated with virulence, namely that virulent strains kill chick embryos at $37^{\circ}$, whereas less virulent strains do not. Our results, moreover, are consistent with the assumption that greater virulence is dependent on a higher rate of multiplication in the chick embryo.

We are grateful to Dr L. H. Collier for his help and criticism.

\section{REFERENCES}

Bedson, H. S. \& Dumbell, K. R. (1961). The effect of temperature on the growth of pox viruses in the chick embryo. J. Hyg., Camb. 59, 457.

Bell, S. D. Jun., Murray, E. S., Carroll, T. J. \& Snyder, J. C. (1963). Studies on trachoma. III. Comparison of virus infectivity for man and chick embryos. Amer. $J$. trop. Med. Hyg. 12, 902.

Collier, L. H. \& Sowa, J. (1958). Isolation of trachoma virus in embryonate eggs. Lancet, i, 993.

Dubes, G. R. \& Wenner, H. A. (1957). Virulence of polioviruses in relation to variant characteristics distinguishable on cells in vitro. Virology, 4, 275.

Dulbecco, R. \& Vogr, M. (1954). Plaque formation and isolation of pure lines with poliomyelitis virus. J. exp. Med. 99, 2.

Furness, G., Graham, D. M. \& Reeve, P. (1960). The titration of trachoma and inclusion blennorrhoea viruses in cell cultures. J. gen. Microbiol. 23, 613.

Gear, J. H. S., Gordon, F. B., Jones, B. R. \& BeLL, S. D. Jun. (1963). Nomenclature of isolates of virus from trachoma and inclusion blennorrhoea. Nature, Lond. 197, 26.

Hanna, L., Jawetz, E., Thygeson, P. \& Dawson, C. (1960). Trachoma viruses isolated in the United States: I. Growth in embryonated eggs. Proc. Soc. exp. Biol., N.Y. 104, 142.

JAwETz, E. \& Hanna, L. (1960). Trachoma viruses isolated in the United States: II. Assay of egg infectivity and stability. Proc. Soc. exp. Biol., N.Y. 105, 207.

Jawetz, E., Hanna, L., Chino, S. \& Zichosch, J. (1962). Trachoma viruses isolated in the United States. V. Growth rates and drug inhibition patterns in embryonated eggs. Proc. Soc. exp. Biol., N.Y. 109, 205.

JoNES, B. R. (1961). TRIC virus infections in London. Trans. ophthal. Soc. U.K. 81,367.

Jones, B. R., Collier, L. H. \& Smrth, C. H. (1959). Isolation of virus frominclusion blennorrhoea. Lancet, i, 902.

Murray, E. S., Bell, S. D. Jun., Hanna, A. T., Nichols, R. L. \& Snyder, J. C. (1960), Studies on trachoma. 1. Isolation and identification of strains of elementary bodies from Saudi Arabia and Egypt. Amer. J. trop. Med. Hyg. 9, 116. 
Nizamuddin, N. \& Dumbell, K. R. (1961). A simple laboratory test to distinguish the virus of smallpox from that of alastrim. Lancet, $\mathrm{i}, 68$.

REeD, L. J. \& MuENCH, H. (1938). A simple method of estimating fifty per cent endpoints. Amer. J. Hyg. 27, 493.

Reeve, P. \& TAverne, J. (1962). A simple method for total particle counts of trachoma and inclusion blennorrhoea viruses. Nature, Lond. 195, 923.

ReEve, P. \& TAverne, J. (1963). Observations on the growth of trachoma andinclusion blennorrhoea viruses in embryonate eggs. J. Hyg., Camb. 61, 67.

T'Ang, F. F., Chang, H. L., Huang, Y. T. \& Wang, K. C. (1957). Studies on the etiology of trachoma with special reference to isolation of the virus in chick embryo. Chin. med.J. $75,49$.

Taverne, J., Blyth, W. A. \& Reeve, P. (1964). Toxicity of the agents of trachoma and inclusion conjunctivitis. J. gen. Microbiol. 37, 271.

Topley and Wilson's Principles of Bacteriology and Immunity (1964). 5th ed. Ed. by G. S. Wilson \& A. A. Miles. London. Edward Arnold and Co. 